ISSN: 2162-3104 Print/ ISSN: 2166-3750 Online

Volume 8, Issue 3 (2018), pp. 1337-1345

(C) Journal of International Students

http://jistudents.org/

doi: 10.5281/zenodo. 1254590

\title{
Structured and Critical Intercultural Programming: Faculty and Staff Collaborate to Put Research into Action
}

\author{
Emily Spitzman \\ Bridgewater State University, USA \\ Michael Waugh \\ Johnson \& Wales University, USA
}

\begin{abstract}
This article describes the origin and curriculum of Identity Dialogues, a program which facilitates conversations about power and privilege among international and domestic students. It was developed as a result of findings from an ethnographic study of an unstructured conversation partner program at the same institution. The study found that power-laden issues were influencing the interactions and confirmed that intercultural competence development has to be actively facilitated (Bennett, 2009). Identity Dialogues sessions start with an examination of participants' own cultural histories and then they are guided to analyze stereotypes and microaggressions. Finally, participants create action steps for fostering intercultural competence in their communities.
\end{abstract}

Keywords: critical intercultural communication, identity, intercultural competence, microaggressions, race

Higher education institutions in the United States provide diverse learning environments. In 2016-17, 1,078,822 international students made up over $5 \%$ of total enrollment in U.S. institutions of higher education (Institute of International Education, 2017). Many institutions are creating opportunities for intercultural learning with the goal of having students become interculturally competent (Bennett, 2009). However, this prioritizing of diversity and intercultural competence development in higher education 
does not always translate to more effective programming for language and culture learning (Jurgens, 2008).

Real intercultural contact is complex and messy, and, in order to facilitate it effectively, such programs have to be well structured (Halualani, 2008). To achieve this goal, however, a close exploration of the complexity of intercultural interactions is necessary. Yet there is a scarcity of research regarding power dynamics in interactions between international and domestic students (Jon, 2012), and issues around power must be integrated into an understanding of these complex interactions. In the first part of this practitioner narrative, we describe key findings from an ethnographic study, analyzing intercultural interaction between international and domestic students, from a critical intercultural communication theoretical perspective (Halualani \& Nakayama, 2010). In the second part of this article, we provide an overview of Identity Dialogues, a structured and critical intercultural program, that was a faculty and staff collaboration designed to apply some of the research findings. Finally, we share several key points about program evaluation and outcomes.

\section{ETHNOGRAPHIC STUDY}

The ethnographic study explored a conversation partner program pairing international and domestic students to meet for weekly conversations about language and culture over a ten-week period. Ethnography was chosen as the method of choice because it facilitated the most comprehensive lens into the conversation partner program experience, focusing intently on the contextual nature of the interactions; the study investigated the students' intercultural encounters through interviews and recorded conversations to see what was happening over the course of the ten-week program. The international students in this study all came from China to complete their degrees in the United States, while all of the domestic students came from the United States. In practice, the conversation partner program experience was unstructured intercultural learning because this program was not integrated into course curricula and participating professors did not actively structure it, and, thus, students did not engage with one another on a deep level. As Pettigrew and Tropp (2008) explain, intergroup contact alone does not always lead to intercultural learning. Some students actually feel frustrated by communication challenges and this frustration may be associated with an increase in prejudice (Spencer-Rodgers \& McGovern, 2002). Given the unstructured nature of this program, the ethnographic study demonstrated that participants in this program did not seem to be developing intercultural competence. Deardorff's (2006) model of 
intercultural competence was used to frame the concept of intercultural competence in this ethnographic study because of its integration of a variety of intercultural experts' models and definitions. In particular, it seemed that participants were not making an effort to see from one another's perspectives, which is the only criteria that all intercultural competence models share (Deardorff, 2006).

Several findings were directly relevant to the creation and development of the Identity Dialogues program. First, international students were not passive participants in the intercultural exchanges and instead they saw themselves as knowledgeable leaders contributing to the interaction. Furthermore, race, socioeconomic status, and gender all emerged from what students had to say about their interaction experiences and from the analysis of their conversations.

Jon (2012) purports that power dynamics in international-domestic student interactions are inadequately examined. From these interviews and conversations, it seemed that there were shifting power dynamics in the interactions between domestic and international students. The international student literature often suggests that international students are disempowered in interactions with domestic students (Hsieh, 2007; MinHua, 2006). However, in this conversation partner experience, this disempowerment did not seem to be present. Although domestic students often spoke for longer periods of time than their international partners during conversations, international students initiated almost as much as the domestic students. In addition, there are a variety of power-laden dynamics, aside from domestic or international student status, that exist in an interaction.

Dimensions such as race, socioeconomic status, and gender appeared to influence the interaction. In contrast to the students who expected the interaction to be easy and had that expectation confirmed, one Black American student shared stories about how she always thinks about her race when she approaches interaction with anyone across cultures. She referenced stories about how, as an African American woman, she always has to think about whether someone will be racist when she interacts with them. She said, "She's Asian. Are they going to look at me weird? Because literally, in my mind I'm like, okay, I'm Black. There's no hiding it. Are they going to look at me weird?" (Interview 1 in Spitzman, 2014). Scollon, Scollon, and Jones (2012) as well as Halualani and Nakayama (2010) emphasize that there is always a power dynamic at play in intercultural communication, a contrast to culture being defined in neutral terms in the intercultural communication literature in the 1980s and 1990s. In this particular case, one domestic student expressed hesitancy and fear about 
how she would be received as an African American woman, underscoring the importance of considering issues of race in intercultural programming.

Additionally, it became clear in the interviews that Chinese students regularly spoke with prejudice about non-Chinese people. In particular, they made some negative comments about Koreans on campus and shared stereotypes about American students, specifically about African American students. These expressions of prejudice show that they do not arrive in the United States with neutral or unbiased views about those who are different from themselves. Likewise, Gresham and Clayton (2011) have found that the challenges that came about in a Community Connections Program included racist attitudes of international students toward other international students on campus.

In addition, socioeconomic status became relevant in the interviews with the domestic students and played a role in their perceptions of international students. When describing their perceptions of international students, domestic students mentioned cars, fashion, and money. Many Chinese students who participated in this study have more than adequate financial resources, which provides a contrast to most of the domestic students enrolled at this university, who have to work and live at home in order to afford their education. This shows, from a critical intercultural communication perspective, that students did not perceive themselves in neutral cultural terms but, instead, in power-laden dimensions, such as socioeconomic status, which plays a role in how students view and approach one another. In Jon's (2012) study of power dynamics between international and domestic students in a Korean context, he found that the economic power of students' home countries was a factor in how students perceived each other and the relative amount of power that they were able to assert.

Furthermore, two of the domestic students mentioned the significance of gender when discussing their international student partners. Female students expressed that they would be more comfortable talking with other students of the same gender. Similar to the point about socioeconomic status, this demonstrates that students saw one another not only in regard to their cultures, but sometimes more significantly in their minds, with respect to their genders and other dimensions of their identities (Jon, 2012). Two male international students said that they would have preferred a male partner because they would have had more to talk about. Thus, perception of what characteristics accompany gender intervened into the conversation partner program experience. Rather than seeing this as a purely cultural exchange of ideas, students thought in terms of social constructs of which they already have well-defined ideas. Scollon, Scollon, and Jones (2012) discuss the notion that national identity is not necessarily 
the most salient difference between people interacting across differences and it is important to note that other parts of their identity might be more significant depending on the situation. Signorini, Wiesemes, and Murphy (2009) also discuss the importance of moving away from national identity as the most critical difference in intercultural communication, as it might not be the difference having the most influence on the interaction at a particular time.

Thus, this ethnographic research on the conversation partner program underscored the power-laden dynamics, such as race, socioeconomic status, and gender that impacted the interactions across culture, pointing to the need for a program that tackles such issues purposefully. Identity Dialogues was created to engage students across differences, challenging them to think critically about dominant and subordinated identities, rather than only learning about cultural and linguistic differences. The next section describes the program in detail, explaining the ways in which it asks students to think about their interactions in power-laden terms.

\section{IDENTITY DIALOGUES CURRICULUM}

The Identity Dialogues program consists of seven weekly one-hour sessions. Identity Dialogues is open to all members of the campus community. Students make up the majority of participants, but staff and faculty occasionally attend. Students enrolled in the ESL program, international business or hospitality majors, student employees from JWU Global (the university's international center), and students who have studied abroad often join the program. Students who are new to campus also tend to join as a way to connect with their peers. Both international and domestic students participate, but international students typically participate at a higher rate. Students participate voluntarily, but some faculty from the ESL and international business programs offer extra credit for their students to participate. On average, there are about 15 students and 3 faculty who participate during each seven-week session (happening once during each trimester).

Participants are not required to attend all seven sessions; however, this is encouraged, as each session builds upon the content of previous sessions. Each academic term, there is typically a cohort that attends most or all sessions and a smaller number of students who attend anywhere from one to three sessions. Some students even attend multiple iterations of the program from term to term. 
Sessions are structured to progress through Kegan's (1982) cultures of embeddedness, which has also been integrated into Bell, Goodman, and Ouellett's (2016) social justice workshop design. This strategy maximizes the opportunity for deep learning to take place through potentially uncomfortable conversations and activities. In addition to following through the stages, described below, we also integrate critical intercultural communication (Halualani \& Nakayama, 2010) into each of our sessions, always asking students to reflect on how issues of power intervene into their experiences of intercultural interaction. Kegan (1982) discusses the environments that are necessary for human beings to make meaning of themselves, others, and the world. The first stage is that of confirmation, where people first get comfortable and open with themselves. Our Identity Dialogues program begins with creating a safe and supportive learning environment where students are assisted by facilitators to examine their own cultural histories and how they were socialized into various belief systems. For example, students do a "Life as a River" activity where they draw a picture of the most important moments in their lives so far, and then they explain this picture to their classmates.

After the confirmation stage, the program moves into the contradiction stage (Kegan, 1982), where participants are guided to question their previously held beliefs and change some of their viewpoints. During this time, participants explore the concepts of stereotypes and microaggressions. Students discuss where stereotypes come from, what their consequences can be, and how to be more aware of the times that our biases influence our thoughts and actions. One such activity involves anonymously writing our own stereotypes down and then discussing them as a group. We ask ourselves about where the stereotypes come from, who holds them, and the ways in which subordinated identities might be put at risk by these stereotypes. During this time, students explore commonalities and differences among stereotypes that different cultural groups hold; many students are surprised that they have never heard of the stereotypes that exist in other countries and begin to see how their views are culturally shaped. During this stage, conversations about where stereotypes come from lead to discussions about how those in power are the ones who often tell the stories about others, creating the stereotypes.

Finally, the program ends in the continuity stage (Kegan, 1982), where participants consider how and where they can apply the material covered in Identity Dialogues to their lives on campus and beyond. For example, one topic of discussion centered on the experience of LGBTQ people feeling more comfortable coming out in the United States, as compared to doing so in their home countries. This led to a conversation 
about how to convince others to become more open and accepting of differences, and the varied strategies necessary to effectively do this in various cultural contexts. One conclusion that students often come to is that personal experience and ideally friendship across differences is often what helps people adapt and become more accepting.

\section{IDENTITY DIALOGUES EVALUATION}

We have not yet conducted formal assessment of learning in the Identity Dialogues program. However, we distributed brief surveys during the first and final sessions to gauge students' understanding of some of the concepts that are examined during the program. To accommodate populations of students that commonly participate in the program, we conducted surveys in English, Chinese, Korean, and Arabic. During the final sessions, facilitators also led focus groups about participants' experiences in Identity Dialogues. Participants' feedback contributes to the continuous revision of the curriculum.

Many students expressed positive learning through their experiences participating in Identity Dialogues. Multiple students have affirmed the confirmation stage (Kegan, 1982). As one participant stated, "It's a safe place. I feel like I can make a mistake and still learn from it." Another student appreciated the opportunity to "have a place to talk about topics that aren't spoken about much. It's refreshing and encouraging to hear others' points of view." Another enjoyed learning about different cultures. This student also said that it is hard for international students to make new friends, and this gave him the opportunity to talk with people from different countries, who have very different beliefs.

Others have noted the importance of the contradiction portion of the program (Kegan, 1982). One student who attended multiple iterations of the program stated that she learns something different every time, as there is the opportunity to develop further learning even if the same topics were covered. Another student stated that "Identity Dialogues has really opened up my eyes to different cultures and the way people from different places interpret different things. It also has helped me realize more about my cultural identity and what makes me who I am." Finally, one student noted, "I love taking time out of the week to simply think about what makes me me." Students mentioned how they do not have the opportunity to think about all of the dimensions of cultural identity in other intercultural interactions. This was a space where students were able to challenge stereotypes and talk openly about discrimination. 


\section{CONCLUSION}

During one of our final sessions, a student participant expressed appreciation for the program, as "understanding each other is the key to improve our society." Olson, Evans, and Schoenberg (2007) argue that " $[t]$ he need for empathic understanding of others' worldviews and life experiences is essential. Feeling comfortable and being capable of interacting with people who are culturally different is basic to being at home in the world" (p. vii). Through this ethnographic research and program creation, we add the notion that critical intercultural communication, which brings race, gender, socioeconomic status, and other power-laden dynamics, into intercultural interaction, is integral to reaching this empathetic understanding.

\section{REFERENCES}

Bell, L.A., Goodman, D.J., \& Ouellett, M.L. (2016). Design and facilitation. In M. A. Adams \& L. A. Bell (Eds.), Teaching for diversity and social justice (pp. 5593). New York: Routledge.

Bennett, J.M. (2009). Cultivating intercultural competence: A process perspective. In D.K. Deardorff (Ed.), The SAGE handbook of intercultural competence (pp. 121-140). Thousand Oaks, CA: SAGE Publications.

Deardorff, D.K. (2006). The identification and assessment of intercultural competence as a student outcome of internationalization at institutions of higher education in the United States. Journal of Studies in International Education, 10(3), 241266.

Gresham, R., \& Clayton, V. (2011). Community connections: A programme to enhance domestic and international students' education experiences. Journal of Higher Education Policy \& Management, 33(4), 363-374.

Halualani, R.T. (2008). How do multicultural university students define and make sense of intercultural contact?: A qualitative study. International Journal of Intercultural Relations, 32(1), 1-16.

Halualani, R.T. \& Nakayama, T.K. (2010). Critical intercultural communication studies: At a crossroads. In R.T. Halualani and T.K. Nakayama (Eds.), The handbook of critical intercultural communication (pp. 1-16). Malden, MA: Blackwell Publishing.

Hsieh, M. (2007). Challenges for international students in higher education: One student's narrated story of invisibility and struggle. College Student Journal, 41(2), 379-391.

Institute of International Education. (2016). International student enrollment trends, 1948/49-2016/17. Open doors report on international educational exchange. Retrieved from http://www.iie.org/opendoors

Jon, J. (2012). Power dynamics with international students: From the perspective of domestic students in Korean higher education. Higher Education, 64(4), 441454. 
Jurgens, J.C., \& Robbins-O'Connell, C. (2008). A comparative study of intercultural and global competency opportunities on American and Irish university campuses. International Education, 38(1), 66-75.

Kegan, R. (1982). The evolving self: Problem and process in human development. Cambridge, MA: Harvard University Press.

Leki, I. (2001). A narrow thinking system: Nonnative-English-speaking students in group projects across the curriculum. TESOL Quarterly, 35(1), 39-67.

Min-Hua, H. (2006). Identity negotiation among female Chinese international students in second-language higher education. College Student Journal, 40(4), 870-884.

Pettigrew, T.F., \& Tropp, L.R. (2008). How does intergroup contact reduce prejudice? Meta-analytic tests of three mediators. European Journal of Social Psychology, 38(6), 922-934.

Olson, C. L., Evans, R., and Schoenberg, R.F. (2007). At home in the world: Bridging the gap between internationalization and multicultural education. Washington, DC: American Council on Education.

Scollon, R., Scollon, S.W., \& Jones, R. H. (2012). Intercultural communication: A discourse approach. Malden, MA: John Wiley and Sons.

Signorini, P., Wiesemes, R., \& Murphy, R. (2009). Developing alternative frameworks for exploring intercultural learning: A critique of Hofstede's cultural difference model. Teaching in Higher Education, 14(3), 253-264.

Spencer-Rodgers, J., \& McGovern, T. (2002). Attitudes toward the culturally different: The role of intercultural communication barriers, affective responses, consensual stereotypes, and perceived threat. International Journal of Intercultural Relations, 26(6), 609-631.

Spitzman, E. (2014). Situated intercultural communication: Domestic and international student interaction (Unpublished doctoral dissertation). University of Rhode Island, Rhode Island.

EMILY SPITZMAN, PhD, is an Assistant Professor in the TESOL Program at Bridgewater State University. She researches critical intercultural communication and language learning across a variety of teaching and learning contexts.

MICHAEL WAUGH, MA, is the Director of the BRIDGE Center at Johnson \& Wales University. He develops and facilitates intercultural programming in higher education. 